\title{
Himalayan Seismic Activity: A Concise Picture
}

\author{
Harihar Paudyal \\ Birendra Multiple Campus, Bharatpur, Chitwan, Tribhuvan University, \\ Correspondence: hariharpaudyal@gmail.com
}

\begin{abstract}
The lofty Himalayan Mountains have formed due to continuous thrusting of the Indian plate under Eurasian plate. The incessant northward movement of the Indian plate generated large amount of strain energy at the plate boundaries which is released in form of earthquake frequently. Large numbers of earthquakes occurred in past signifies that the Himalayan region is seismically very active. The b-value for the central Himalayan region is determined as 1.15 which defines the level of seismic activity of a region.
\end{abstract}

Keywords: anomalous seismicity, central himalaya, seismic activity, b-value.

\section{Seismicity of Himalayas}

Among the entire natural disasters earthquake is the worst. An earthquake is a series of vibrations on the earth's surface caused by the generation of elastic (seismic) waves due to sudden rupture within the earth during release of accumulated strain energy (Richter, 1958). Faulting may be considered as an immediate cause of an earthquake. Due to constant movement of plates, deformation is caused which results generations of large amount of strain energy. It is impossible to prevent earthquakes from occurring. However, the disastrous effects of these can be minimized appreciably through scientific understanding of their nature, causes, frequency, magnitude and areas of influence. If the earthquake occurs in a populated area, it may cause many deaths and injuries and extensive damage of property.

The Himalayas where it is standing at present was covered with an ocean named Tethys some $200 \mathrm{Ma}$ years ago. The Himalayas was formed by northward movement of Indian landmass after its fragmentation from the Gondwanaland which closed the Tethys ocean and collided with Eurasia at its southern margin some $65 \mathrm{Ma}$ years ago (Yin, 2006). So formation of Himalayas is due to the result of continent- continent collision along a line called Indus Tsangpo Suture. It is situated at northern boundary of the Indian plate.
Based on the latest concept of plate tectonic model of the earth, the Himalayan region falls in the seismic region where frequently devastating earthquakes have occurred. Indian plate is moving in north-northeast direction and colliding with Eurasian plate along the Himalayas. The region is characterized by three major northward dipping thrust zones separated by geological/ physiographic sub-provinces. The northern most part is the greater Himalaya, which has an average elevation of $5 \mathrm{~km}$.

The seismicity of Himalayas is associated with northward drifting of Indian plate and interaction with Eurasian landmass. The subduction of Indian plate does not exist in the Himalayan foot hill below the Tibetan plateau. However, the region is seismically very active in which large numbers of earthquakes (small to great) has occurred in the past and are occurring at present but diffused. During the last over 100 years, four strong earthquakes with $M>8$ have occurred in Himalayas. These are: Shillong plateau earthquake in 1897 (M 8.7); Kangra earthquake in 1905 (M 8.5); Bihar-Nepal border earthquake of 1934 (M 8.4) and Assam earthquake of 1950 (M 8.7) (Fig. 1). Besides, a number of moderate to large earthquakes have occurred in the region such as 1912 (M 8); 1916 (M 7.5); 1918 (M 7.6); 1930 (M 7.1); 1936 (M 7.0); 1946 (M 7.8); 
1947 (M 7.8); 1951 (M 8) and 1952 (M 7.5); Bajhang earthquake of 1980 (M 6.5); Udayapur earthquake of 1988 (M 6.6); Uttarkashi earthquake of 1993 (M 6.2),

Great Earthquakes in Central Himalayas ' (1897-1950)

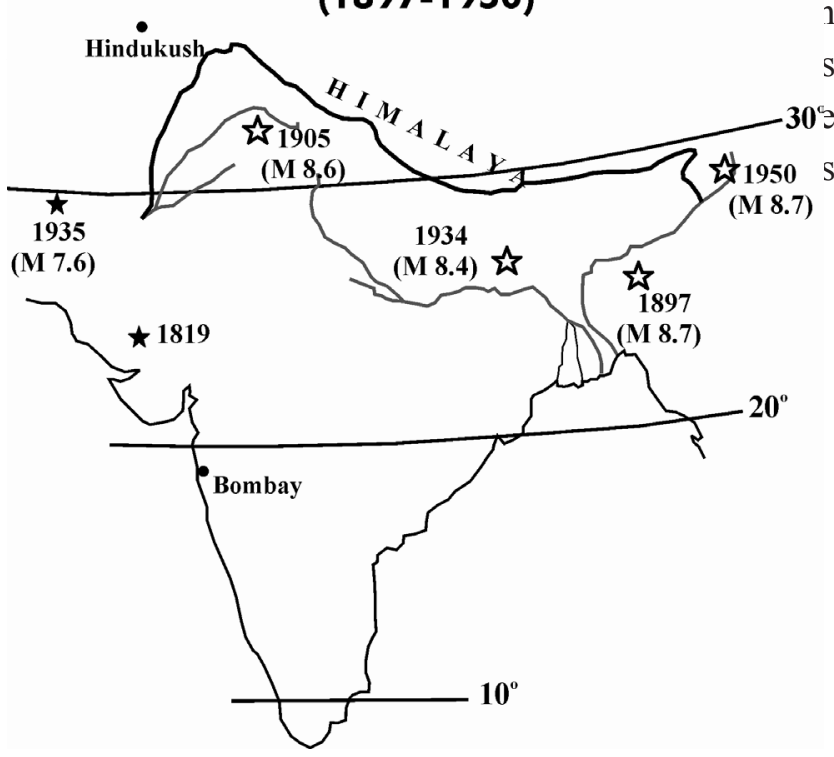

Fig. 1: Map of India and its surrounding region showing location of Great Indian Earthquakes along with their magnitude in bracket and some other destructive earthquakes.

The seismicity of Himalayas can be classified into four zones as: 1) Kashmir- Himachal Himalayas; 2) IndiaWest Nepal Himalayas; 3) Nepal-Sikkim Himalayas; and 4) Northeast India- Burma Himalayas. Large number of research articles reflect seismicity change i.e. b-value for different zones, seismic risk factors and hazard analyses of the Himalayan region. About 85\% of the total earthquakes of the Himalayan region are within top $40 \mathrm{~km}$ crustal portion whereas $\sim 10 \%$ show their focal depth ranging from 40 to $70 \mathrm{~km}$ and the remaining 5\% events are intermediate that occur from 71 to $125 \mathrm{~km}$ depth.

Nepal lies at the boundary between Indian and Tibetan plates and is characterized by an intense seismic activity. The current seismic activity in Nepal is directly related to the collision between India and Eurasia. On the basis of chronological history of earthquakes, Nepal constitutes one of the seismically active regions of the world. A narrow belt that runs along the topographic front of the Higher Himalaya, from west to east, is more active. All seismic activity within the Nepal territory is due to stress release along the major faults. A great and a number of moderate earthquakes as 1934 (M 8.4), 1980 (M.5), 1988 (M 6.6) have been occurred in Nepal during last 70 years which caused the loss of lives and properties in the region. The epicenter of the 1988 Udayapur event is found quite close to that of the great earthquake of 1934

Two different regions one in east and another in west part of Nepal have high micro-seismic activity. It is obtained, between $29^{\circ} \mathrm{N}$ and $30.5^{\circ} \mathrm{N}, 80^{\circ} \mathrm{E}$ and $82^{\circ} \mathrm{E}$ in western Nepal and $86.5^{\circ}$ and $87^{\circ}$ in eastern Nepal close to the MCT, a number of events having magnitudes 6.0 or greater have occurred in the past. The seismicity between $82^{\circ} \mathrm{E}$ and $86.5^{\circ} \mathrm{E}$ is relatively low and fairly scattered (Chandra, 1978, Verma and Kumar, 1987). The local seismic network data also showed the same trend (Pandey et al., 1999). In western and central Nepal micro-seismic activities tend to cluster in front of the higher Himalaya and it extends further south in eastern Nepal. Those are, the 1980 Bajhang earthquake (M 6.5) in western, the 1988 Udayapur earthquake (M 6.6) in eastern region. Earthquakes in this subduction region are mostly of shallow depth. However some intermediate depth events occurred in Western Nepal, Eastern Nepal (Mt. Everest region) and the adjoining south central Tibet region. Historical seismicity of the Himalaya implies that the slip on the main frontal thrust is frequently accommodated by $\mathrm{M} \geq 8$ shallow earthquakes, but shows a seismic gap in western Nepal (Khattri, 1987). A 500 to $800 \mathrm{~km}$ long segment between the epicenters of the great 1934 Nepal-Bihar and the 1905 Kangra earthquakes has not experienced a major quake for more than 200 years (Bilham et al., 1995). This seismic gap reflects a long live elastic strain accumulation and represents a potential zone for future seismic hazard.

In case of a single such future great event in the Himalayan region, Wyss (2005) quantitatively estimated potential losses of 150,000 human lives and more than 300,000 will be injured and $\sim 3,000$ settlements will be affected. This estimated human loss shows if such event occur around the Kathmandu the loss will be 21-42 thousands and number of injured may cross $45-86$ thousands. 


\section{Seismicity level: b- value}

It has been observed that the general distribution of earthquakes over the observed range of magnitudes can be represented as:

$\log _{0} \mathrm{~N}=\mathrm{a}-\mathbf{B}$

where $\mathbf{b}$ is the gradient of straight line and $\mathbf{a}$ is a constant representing the characteristics of a region, and $\mathrm{N}$ is the cumulative number of earthquakes of magnitude $\mathrm{M}$ or greater than $\mathrm{M}$ per unit time (Guenberg and Richter, 1954). The constant b defines the seismicity level of seismic activity of a region. Frequently, it is of great importance to study the seismicity of a limited area. For this purpose, highly sensitive seismographs are installed in and around the area. After collecting the data for several years, the $\log \mathrm{N}$ is estimated and plotted against magnitude on $\mathrm{x}$-axis and the gradient thus estimated from the graph provides measure of b-value. Based on laboratory experiment, suggested that $b$-value varies with material heterogeneity. An inverse relationship between $b$-value and stress in a volume of rock has already been established. High $\mathrm{b}$-value is found to be associated with existence of the magma chambers. It is observed that stress is the single-most important factor affecting b-values. Higher b-value indicates lower stress, and hence measurements of b-value help infer the stress regime in a volume of rock (Paudyal, 2008).

Using the seismic data for the period 1963 to 2006, the relation established for the Central Himalaya Nepal region as: $\log N=7.98-1.15 \mathrm{M}$. The curve fits best for the data with magnitude 4.4 and above, which represents the cutoff magnitude 4.4 for the whole study area and the $b$ value is estimated to be 1.15. (Fig. 2)

The b-values represent the different types of seismicity in different seismotectonic environment. It may be related to the properties of the medium and the prevailing stress condition in the localities. The b-values estimated here for central Himalaya region is 1.15 which is higher than the normal value, i.e.1, representing a compressed region.

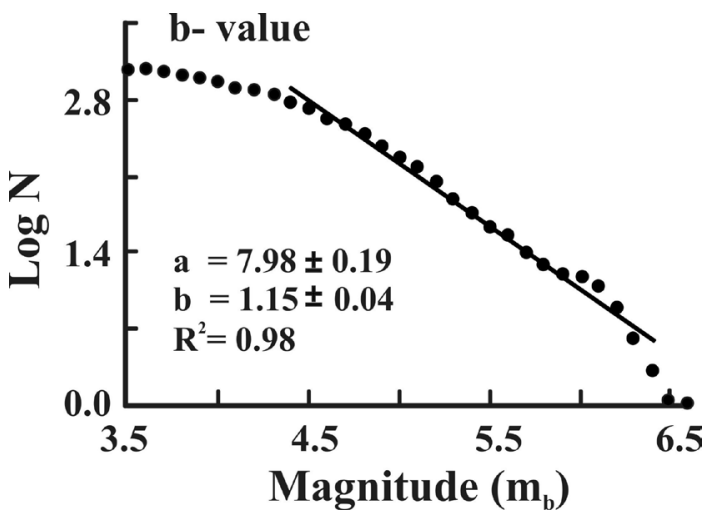

Fig. 2: b- value estimates for Central Himalayan region using earthquake data from 1963 to 2006.

\section{Conclusion}

An earthquake is a sudden movement of the Earth, caused by the abrupt release of strain energy that has accumulated over a long period in the region. Himalaya region is seismically active region where earthquakes of different magnitudes have been occurring frequently. The region has several potential zones for the future seismic activity which may cause huge loss of lives and property. The b-values estimated using the earthquake data for the period 1963-2006 for central Himalaya region is 1.15 which represents the region is highly compressed.

\section{References}

Bilham, R., P Bodin and M Jackson, 1995, Journal of Nepal Geological Society, 11, 73-88.

Chandra, U, 1978, Physics of the Earth and Planetary Interiors, 16, 109-131.

Gutenberg, B and CF Richter, Seismicity of the Earth and Associated Phenomena, Hafner, 1954.

Khattri, KN, Tectonophysics, 138, 79-92, 1987.

Pandey, MR, RP Tandukar, JP Avouac \& T Heritier, 1999, J. of Asian Earth Sci., 17, 703-712.

Paudyal H, 2008, Seismicity and seismotectonics of Nepal and its adjoining region, $\mathrm{Ph}$. D. thesis submitted to Banaras Hindu University, Varanasi, India (unpublished).

Richter, CF, Elementary Seismology, W.H. Freeman and Company, San Francisco, USA, 1958.

Verma, R K and K Kumar, 1987, Tectonophysics, 134, 157-175.

Wyss, M, Natural Hazards, 34, 305-314, 2005.

Yin, A, Earth Science Reviews, 76, 1-131, 2006. 